not functional constituents present in all plants, but can only be obtained from particular species of plants. Apart from this restricted taxonomic distribution, these compounds often have no obvious metabolic function but represent a fascinating challenge to the organic chemist, to the plant biochemist, to the taxonomist and to any scientists interested in the tremendous variety of chemical substances which are produced by this "secondary" metabolism.

Apart from a full account of our general knowledge in this field, the use of plant geneties in secondary metabolism is described in detail. Dr. Bu'lock also links the specific problems of secondary metabolism with general enzy. mology where this is appropriate. The volume represents a comprehensive and at the same time concise account of this increasingly important field. It is, however, written primarily from the standpoint of the organic chemist interested in natural products, and assumes in the reader a fairly sophisticated knowledge of reaction mechanism and modern theoretical organic chemistry. It is doubtful whether the botanist or mycologist whose chemical knowledge may have been acquired 15 or 20 years ago will find it easy to follow the detailed chemical arguments which are used. The author is, however, careful to point out the limitations of our present technique, and the fragmentary character of our knowledge, and indicates clearly where further progress may be expected.

A. Neuberger

\section{STICKINESS AND CANCER}

\section{Hyaluronidase and Cancer}

By Ewan Cameron. Pp. xiii +245. (London and New York: Pergamon Press, Ltd., 1966.) 50s, net.

Dr. Cameron's stimulating book presents a thesis which is stark in its simplicity. The excessive secretion of hyaluronidase is the beginning, the middle and the end of the problem of eancer.

According to Dr. Cameron, neoplastic cells arise as the result of the interaction of any carcinogenic stimulus with the protein-mucopolysaccharide ground substance, as a result of which the latter becomes increasingly viscous and impermeable. Adjacent normal cells attempt to maintain their normal environment by the increased release of hyaluronidase. "Each cell in the body is firmly embedded in a sticky viscous cement of ground substance" which is attached by hyaluronidase. Contact between the cells is reduced and this in turn permits or stimulates cell division. The preferential nutrition of tumour cells is the result of local increased stromal and capillary permeability evoked by hyaluronidase secretion. Malignant infiltration and the formation of metastases are likewise due solely to the action of the enzyme on the surrounding normal tissues and the walls of blood and lymph vessels.

Dealing first with the application of Dr. Cameron's ideas to carcinogenesis, it is very difficult to understand how his mechanism of carcinogenesis could account for the in vitro malignant transformation of normal cells by viruses, carcinogens, X-rays or "spontaneously". Dr. Cameron appears to be either unaware of, or to ignore, the considerable body of work published in recent years establishing the existence of tumour-specific antigens in many experimentally induced animal tumours, and the possible role of the immune response in the development of these tumours.

On the subject of the irreversible nature of the neoplastic transformation, the author considers that it is clearly a matter of cellular inheritance, but rejects the view that interaction between DNA and a carcinogen is involved, even in the initiation, with the rather cavalier phrase "there is not a shred of evidence to support its validity".
Potter's deletion theory and Warburg's hypothesis are not mentioned.

When it comes to the role of cell contact in regulating cell proliferation, the author probably finds more common ground with other workers in this field. He carries the cell contact mechanism of cell proliferation much further than most, particularly when he ascribes loss of cell contact solely to the secretion of hyaluronidase. This enzyme, incidentally, has so far proved remarkably ineffective in dispersing cells in tissues. Tumour cell nutrition is dealt with without mentioning the greater capacity for glycolysis or other changes in metabolic processes which have been extensively investigated.

The release of hyaluronidase by tumour cells has been considered by many investigators to play a part in malig. nant invasion, but the evidence is contradictory, and Dr. Cameron's review of it does not convince this reader that hyaluronidase is the only, or even the main, enzyme system contributing to invasion. Assessing the evidence is not made easier when the role of proteolytic enzymes is dismissed in four lines.

Dr. Cameron's arguments are presented very clearly and with a coherence which is, perhaps, gained at the cost of omitting a considerable amount of established work which does not fit in with his thesis.

This book should serve a useful purpose by stimulating many investigators in the field of cancer research to reexamine carefully the basis of many of the concepts currently held. The author has made a very extensive survey of the literature pertaining to the role of hyaluronidase in cancer, which is extremely useful. G. C. EAsty

\section{BEHAVIOUR AND NUCLEIC ACIDS}

\section{Macromolecules and Behavior}

Edited by John Gaito. Pp. ix + 197. (Amsterdam: NorthHolland Publishing Company; New York: AppletonCentury-Crofts, a Division of Meredith Publishing Company, 1966.) 29 guilders; $58 s$.

THIs little book has brought together some fascinating articles in a rather unusual field. They are directed in the main at the role of RNA and DNA in determining behaviour, although nearly all the experimental evidence relates to the changes in the macromolecules following on experimental procedures. Except in the last chapters, where K. H. Pribham and others present their theoretical treatment of the basis of memory, there is often a fairly tenuous connexion between the experimental data presented and rather gross behavioural patterns. Nevertheless, the book has gathered between its covers a very valuable and readable series of papers.

The chapter by Ochs on axoplasmic flow is an excellent summary of the recent work on transport of molecules of many kinds along the axoplasm. The chapter by Pevzner is a review of, among other topics, eytospectrophotometric methods; in the original material presented, it reveals the great extent to which such techniques have developed in the Soviet Union. Pevzner's chapter is the most provocative, as he modestly, but thoughtfully, raises the question in his brief summary as to just what the relationship is between the nucleic acids and behaviour, and just how far the biochemists can at present go in finding a meaningful answer. The difference in the time seales between the laborious and time-consuming procedures of the biochemist on the one hand, and the speed of action in nerve cells as demonstrated by the electro-physiologist, on the other, is so enormous that one rightly asks : can the two approaches ever meet?

In spite of such difficulties, this book shows that in a surprising number of instances correlation is possible, even with the attempt to show that treatment of certain types of elderly individuals with RNA leads to an improve- 